\title{
Sentidos de família e o desafio para a intersetorialidade na proteção social
}

\author{
Meaning of Family and the Challenge \\ for Intersectoriality and Social Protection
}

\author{
Elizete Matias Barbosa Orozimbo ${ }^{a}$ \\ (D) http://orcid.org/0000-0001-9399-4283 \\ Maria Lúcia Miranda Afonsob \\ (D) https://orcid.org/0000-0002-1019-6946
}

Resumo: $O$ artigo relata uma pesquisa qualitativa documental, comparando sentidos da família nas políticas de Saúde, Educação e Assistência Social, entre 1988 e 2015, no Brasil. Foram analisados 21 documentos, como campo discursivo relevante, ainda que não exaustivo. Usando a análise crítica do discurso, o artigo discute o lugar estratégico da família nessas políticas como: objeto, instrumento, parceira e/ou sujeito de direitos, envolvendo contradições na intersetorialidade na proteção social.

Palavras-chave: Família. Políticas públicas. Saúde. Educação. Assistência Social. Intersetorialidade.

\begin{abstract}
The article reports a qualitative documentary research, comparing the meanings of the family in the policies of Health, Education and Social Assistance, between 1988 and 2015, in Brazil. The research analyzed 21 documents, as a relevant discursive field, yet not exhaustive. Using Critical Discourse Analysis, it discusses the strategic place of the family in such policies: object, instrument, partner and /or subject of rights, pointing contradictions to intersectoriality in social protection.
\end{abstract}

Keywords: Family. Public policies. Health education. Social assistance. Intersectoriality. 


\section{Introdução}

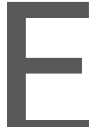

sta pesquisa, de natureza qualitativa e descritiva, buscou compreender os sentidos atribuídos à relação entre família e proteção social no campo discursivo das políticas de Saúde, Educação e Assistência Social. Inicia-se com uma breve discussão sobre família e proteção social. Em seguida, descreve a metodologia e o resultado da pesquisa, apontando dificuldades na construção da intersetorialidade e na integralidade das políticas públicas quando trabalham com diferentes abordagens de família. Nas considerações finais, são apontados limites e potencialidades da presente pesquisa.

\section{Família e proteção social: uma breve discussão}

Assume-se, nesta pesquisa, que proteção social é "um conjunto de iniciativas públicas ou estatalmente reguladas para a provisão de serviços e benefícios sociais com objetivo de enfrentar situações de risco social ou privações sociais" (Jaccoud, 2013, p. 58). Conforme Cotta (2009), é responsabilidade do poder público desenvolver ações coletivizadas para enfrentar riscos sociais e vulnerabilidades intrínsecas à condição humana e que ocasionam insegurança.

Considera-se que a desproteção social se materializa em situações como pobreza, e/ou em aspectos subjetivos, como valores, identidades, crenças, comportamentos, ou ainda em dimensões relacionais, que reforçam a produção e a reprodução da pobreza, a violação de direitos e padrões de subalternidade (Carneiro, 2010), bem como em fatores que ocasionam a restrição de acesso às políticas públicas.

Assim, o desenvolvimento social requer a responsabilização do Estado, a efetiva participação da sociedade em projetos de combate à pobreza e à marginalização, o desenvolvimento econômico distributivo, equitativo e equânime, a igualdade de oportunidades e participação democrática e cidadã (Cotta, 2009). 
A família, como unidade social de apoio, ao mesmo tempo em que sofre com vulnerabilidades como pobreza, violência e outras formas de insegurança social, torna-se elemento essencial para o desenvolvimento social. Ela passa a ser sujeito de direito à proteção do Estado e sujeito de deveres no tocante à responsabilização pela proteção de seus membros (Saraiva, 2016), o que gera uma tensão entre o público e privado na transição dos modelos tutelar e assistencialista para o modelo protetivo de proteção social. Daí a importância de se pesquisar o seu lugar nas políticas públicas e na proteção social.

\subsection{O lugar estratégico da família nas políticas públicas}

A família assume lugar estratégico na dialética entre Estado e sociedade como elemento-chave para a sobrevivência dos indivíduos e para a proteção e socialização de seus membros, na transferência de capital cultural, econômico e de propriedade e nas relações de gênero, de solidariedade (Carvalho, 2003) e de coletividade. Investiga-se os sentidos que lhe são atribuídos como objeto, instrumento, parceira ou sujeito de direitos nas políticas públicas.

\subsubsection{A família como objeto da política pública}

O sentido de família como objeto de políticas públicas liga-se ao modelo de proteção social pautado no paradigma econômico (Cotta, 2009), que vigorou no Brasil no período de 1930 a 1980, numa perspectiva de controle de padrões familiares que não produzissem problemas para o Estado (Souza, 2000; Faria, 2004; Saraiva, 2016).

Nesse período, a política de Saúde mantinha uma perspectiva higienista, com intervenções de caráter moralizante e disciplinador sobre a família (Saraiva, 2016). A Educação reforçava o modelo de família nuclear consonante com o modelo de desenvolvimento econômico (Medeiros, 
2014). A Assistência Social abordava a família pobre, ou diferente do modelo nuclear, pela dicotomia entre capacidade ou incapacidade para cuidar de seus membros, culpabilizando-a como incapaz e/ou desestruturada (Faria, 2004). É com a Constituição Federal de 1988 (CF88) que se produz uma transformação, à medida que as políticas públicas passam a reconhecer a família como uma referência para a consolidação dos direitos sociais.

Refletindo sobre essas raízes históricas, indaga-se se persistem nas políticas públicas, traços ideológicos que reafirmam modelos tradicionais de família, deslegitimando a diversidade de arranjos familiares no contexto social, econômico, político e cultural (Orozimbo, 2017).

\subsubsection{A família como instrumento da política pública}

O sentido atribuído à família como instrumento das políticas públicas está ligado às situações em que os membros das famílias são convocados para executar ações que seriam atribuições dos serviços públicos, ou que dariam suporte a esses serviços, ou ainda quando a família é utilizada como instituição redistributiva (Souza, 2000; Faria 2004), atuando como ponte para a concretização da proteção social do Estado na melhoria das políticas públicas.

Esse sentido de instrumento se materializa, por exemplo, na Saúde, nas situações em que fica a cargo da família levar idosos e pessoas com deficiência para tratamento, viabilizando o acesso ao direito à saúde. $\mathrm{Na}$ Educação, quando a família é responsabilizada por levar crianças e adolescentes para a escola para a garantia do acesso, com ou sem retaguarda de transporte público escolar. Na Assistência Social, por exemplo, quando o Programa Bolsa Família condiciona a segurança de renda à matrícula e à frequência escolar dos filhos, tornando a família um instrumento para o acesso ao direito à educação, independentemente do apoio para viabilizar esse acesso. 


\subsubsection{A família como parceira da política pública}

O sentido atribuído à família como parceira se concretiza nas situações em que o Estado a considera como parte da rede de proteção social para provisão de bem-estar de seus membros, reconhecendo sua importância por agregar recursos próprios àqueles fornecidos pelo Estado (Teixeira, 2015). Há diferença entre ser mero instrumento ou ser parceira, desde que o Estado reconheça a necessidade do apoio às famílias para que desempenhem suas funções protetivas.

Nos textos legais, esses sentidos podem ser vistos, por exemplo, na Educação, quando se reconhece que a família contribui para o desenvolvimento integral das crianças e adolescentes em seus aspectos físico, psicológico, intelectual e social e que, nesse sentido, é fundamental o seu diálogo com a escola (Brasil, 2014). Na Saúde, a parceria ocorre, por exemplo, na construção e no desenvolvimento de projetos terapêuticos e responsabilização da família e do indivíduo pelo cuidado e pela prevenção de doenças (Brasil, 2006), desde que com a orientação por parte de profissionais da saúde. Na Assistência Social, a parceria com a família se apresenta na provisão de cuidados para seus membros de forma complementar aos serviços, programas, projetos e benefícios (Brasil, 1993, 2004, 2009 e 2015), cujo desenvolvimento precisa da pactuação e da adesão das famílias ao trabalho social para afiançamento das seguranças sociais.

\subsubsection{A família como sujeito de direitos relacionados às políticas públicas}

No discurso dos textos legais da Saúde, Educação e Assistência Social, produzidos após a CF88, notam-se avanços na abordagem da família como sujeito de direitos, uma vez que, mesmo quando ela é demandada como instrumento ou parceira, é também convocada, com a comunidade, a participar das instâncias de controle social e de outros 
espaços democráticos. Obviamente, não basta que a participação social conste na lei. É preciso que exista na realidade social, reconhecendo a capacidade das famílias de participar nas políticas públicas.

Nos textos da Saúde, nesse período, é claro o reconhecimento de que as famílias precisam fazer parte do fortalecimento das instâncias de controle social e de participação popular (Brasil, 1990). Na Educação, preconiza-se a mobilização das famílias, da comunidade e de setores da sociedade civil e fomento às experiências de educação popular e cidadã como responsabilidade de todos e incentivo à formação de grêmios estudantis, associação de pais, entre outros (Brasil, 2014). Na Assistência Social, enfatiza-se a participação da família nas instâncias de controle social e na gestão democrática da política, e o desenvolvimento do trabalho social com famílias é visto como um espaço de discussão e desenvolvimento de projetos coletivos voltados para o protagonismo da sociedade (Brasil, 2012).

Apesar dos avanços legais no discurso das políticas públicas, a relação do Estado com as famílias - e os diferentes arranjos familiares - precisa ainda superar velhos estereótipos que influenciam, de forma direta ou indireta, no desenho das políticas. É possível encontrar, em uma mesma política pública, serviços ou programas que abordem as famílias de formas diferentes. Também nas articulações intersetoriais, pode haver descompasso entre políticas públicas na maneira de trabalhar com as famílias.

\section{Procedimentos metodológicos}

A pesquisa documental foi desenvolvida utilizando-se o referencial teórico-metodológico da Análise Crítica do Discurso, de Norman Fairclough (1989, 2001, 2003, 2010) e dele com Melo (2012). Nessa abordagem, são estudados os sentidos produzidos, seus efeitos e interligações com as práticas e relações sociais (Resende, 2011, p. 23). O discurso é considerado uma prática política investida de possibilidades de manutenção e/ou de transformação das relações de poder (Fairclough, 2001). Pensa-se, 
com Foucault (2014, p. 66), que a linguagem é "uma prática que constitui o social, os objetos e os sujeitos sociais", e sua análise, numa perspectiva crítica, configura uma forma de questionar as instâncias de controle.

A relação dialética entre discurso e sociedade expressa e colabora para construir mudanças nas práticas discursivas e sociais (Pedrosa, 2005; Resende, 2011). Considerou-se que os textos legais figuram como diretrizes e normativas que refletem vozes políticas de estudiosos, técnicos, da sociedade e do próprio governo, balizando práticas que podem reforçar modelos ideológicos e políticos históricos no Brasil.

O corpus (conjunto de documentos) da pesquisa foi composto por 21 documentos oficiais de políticas públicas, sendo nove da Saúde, ${ }^{1}$ três da Educação ${ }^{2}$ e nove da Assistência Social. ${ }^{3}$ Foram escolhidos por sua centralidade nas políticas abordadas e neles foram analisados as visões de proteção social e os sentidos de família, descritos como: objeto, instrumento, parceira e/ou sujeito de direitos.

As categorias de análise foram: o lugar da família como objeto, instrumento, parceira e/ou sujeito de direitos nas políticas de Saúde, Educação e Assistência Social; os sentidos dados aos diferentes arranjos

1 Documentos analisados na política de Saúde: Lei n. 8.080, de 19 de setembro de 1990 (S1); Lei n. 8.142, de 28 de dezembro de 1990 (S2); Lei n. 9.836, de 23 de setembro de 1999 (S3); Lei n. 10.216, de 6 de abril de 2001 (S4); Portaria n. 2.528, de 19 de outubro de 2006; (S5) Portaria n. 648/Gm, de 28 de março de 2006 (S6); Portaria n. 3.088, de 23 de dezembro de 2011 (S7); Portaria n. 1.130, de 5 de agosto de 2015 (S8); Plano Nacional de Saúde 2016/2019 (S9).

2 Documentos analisados na política de Educação: Lei n. 9.394, de 20 de dezembro de 1996 (E1); Lei n. 13.005, de 25 de junho de 2014 (E2); Plano Nacional de Educação 2014-2024 (E3).

3 Documentos analisados na política de Assistência Social: Lei n. 8.742, de 7 de dezembro de 1993, atualizada pela Lei n. 12.435, de 2011 (AS1); Política Nacional de Assistência Social — PNAS (2005) (AS2); Orientações Técnicas do Centro de Referência de Assistência Social — CRAS (2009) (AS3); Protocolo de Gestão Integrada de Serviços e Benefícios de Transferência de Renda no Âmbito do Sistema Único de Assistência Social — Suas (2009) (AS4); Orientações Técnicas sobre o PAIF, v. 1. Tipificação Nacional dos Serviços Socioassistenciais (AS5); Orientações Técnicas sobre o PAIF, v. 2. Trabalho social com famílias do Serviço de Proteção e Atendimento Integral à Família — PAIF (2012) (AS6). Norma Operacional Básica (2012) (AS7); Concepção de Convivência e Fortalecimento de Vínculos (AS8); Caderno de Orientações — Serviço de Proteção e Atendimento Integral à Família e Serviço de Convivência e Fortalecimento de Vínculos: articulação necessária na Proteção Social Básica (AS9). 
familiares; o sentido dado à capacidade de participação e de decisão das famílias nos espaços de controle social e a intersetorialidade nas políticas de proteção social à família.

\section{Análise dos dados}

Os quadros a seguir apresentam a estrutura analítica da pesquisa com as categorias de análise, as questões analisadas e a síntese dos resultados. No Quadro 1, pode-se ver que, dentro de uma mesma política, existem diferentes sentidos atribuídos à família, os quais são, muitas vezes, de instrumento ou de parceira.

Quadro 1. Síntese dos resultados sobre sentidos atribuídos à família

\section{Categoria de análise}

1. O sentido da famí- 1.10 documento faz relia na política social ferência à família para como objeto, instru- efetivação dos direitos mento, parceira e/ou que a política social deve sujeito de direitos promover e garantir?

1.2 Que argumentos o documento usa para a concretização de tais objetivos?

1.3 Como o documento trata a relação da família com a política social: objeto, instrumento, parceira ou sujeito de intervenção na sociedade?

\section{Síntese dos resultados da análise}

Saúde

Educação

Assistência

Social

Saúde

Educação

Assistência

Social

Saúde

A família é um objeto do Programa Saúde da Família e é parceira no cuidado e desenvolvimento de projetos terapêuticos para o paciente da saúde mental e do idoso, por exemplo.

Educação A família é um instrumento para a alfabetização de seus membros por meio da cooperação e da participação no dever de casa.

Assistência A família é um instrumento do ProSocial grama Bolsa Família para ampliação de acesso aos direitos da saúde e da educação e é parceira na divisão de responsabilidades e provimento da proteção de seus membros.

Fonte: Elaboração das autoras. 
No Quadro 2, são resumidos os resultados referentes à concepção de responsabilidade da família e do Estado nos documentos estudados. Observa-se que, por mais que se aponte que a família precisa ser protegida para dar conta de suas funções protetivas, dela ainda se espera grande participação no cuidado de seus membros mais frágeis, complementando as políticas públicas ou viabilizando a sua efetividade.

Quadro 2. Síntese dos resultados sobre sentidos atribuídos à responsabilidade da família e do Estado

\begin{tabular}{|c|c|c|c|}
\hline $\begin{array}{l}\text { Categoria } \\
\text { de análise }\end{array}$ & $\begin{array}{l}\text { Questões } \\
\text { analisadas }\end{array}$ & \multicolumn{2}{|r|}{ Síntese dos resultados da análise } \\
\hline \multirow[t]{3}{*}{$\begin{array}{l}\text { 2. Responsabili- } \\
\text { zação da famí- } \\
\text { lia e do Estado } \\
\text { diante da garan- } \\
\text { tia de direitos }\end{array}$} & \multirow[t]{3}{*}{$\begin{array}{l}2.2 \text { O que se es- } \\
\text { pera que a polí- } \\
\text { tica realize como } \\
\text { responsabilidade } \\
\text { do Estado e o que } \\
\text { se subentende no } \\
\text { documento como } \\
\text { responsabilidade } \\
\text { das famílias e dos } \\
\text { indivíduos? }\end{array}$} & Saúde & $\begin{array}{l}\text { Cabe ao Estado a obrigação de fazer conhecer } \\
\text { os direitos da saúde no atendimento e desenvol- } \\
\text { vimento de ações para todos os portadores de } \\
\text { transtorno mental (S4), na assistência à saúde da } \\
\text { família, materno infantil, internação, cuidados no } \\
\text { domicílio e outros. À família cabe a prática do cui- } \\
\text { dado familiar ampliado por meio de intervenções } \\
\text { que influenciem nos processos de saúde-doença } \\
\text { dos indivíduos, da família e da comunidade. Em } \\
\text { muitos casos, subentende-se que a família faça a } \\
\text { mediação (busque) para o acesso à saúde. }\end{array}$ \\
\hline & & Educação & $\begin{array}{l}\text { Preconiza-se como responsabilidade do Estado } \\
\text { que os estabelecimentos de ensino proponham } \\
\text { ações para a recuperação dos alunos de me- } \\
\text { nor rendimento; articule-se com as famílias } \\
\text { e a comunidade; crie processos de integração } \\
\text { da sociedade com a escola; informe aos pais, } \\
\text { conviventes ou não com seus filhos, e, se for o } \\
\text { caso, os responsáveis legais, sobre a frequência } \\
\text { e rendimento dos alunos; execute a proposta } \\
\text { pedagógica da escola; notifique ao Conselho Tu- } \\
\text { telar do município, ao juiz competente da comar- } \\
\text { ca e ao respectivo representante do Ministério } \\
\text { Público a relação dos alunos que apresentem } \\
\text { quantidade de faltas acima de } 50 \% \text {. À família } \\
\text { cabe matricular os filhos e dar assistência na } \\
\text { formação educacional dos mesmos (E1). }\end{array}$ \\
\hline & & $\begin{array}{l}\text { Assistência } \\
\text { Social }\end{array}$ & $\begin{array}{l}\text { Preconiza como responsabilidade do Estado o } \\
\text { provimento de serviços, programas e projetos, } \\
\text { com foco prioritário de atenção às famílias, seus } \\
\text { membros e indivíduos. Cabe ainda o financia- } \\
\text { mento nas três esferas de governo e definição } \\
\text { de competências para os entes federados (AS1). } \\
\text { À família cabe a mediação das relações entre o } \\
\text { sujeito e a coletividade. É também esperado que } \\
\text { a família respeite os direitos de seus membros, } \\
\text { cuidando dos idosos ou não incidindo em vio- } \\
\text { lência contra crianças e adolescentes. }\end{array}$ \\
\hline
\end{tabular}

Fonte: Elaboração das autoras. 
No Quadro 3, são colocadas as concepções de família nos documentos analisados. Os resultados apontam ambivalência e conflito entre, por um lado, a concepção discursiva familista e tradicionalista e, por outro, o discurso crítico que valida diferentes arranjos familiares no contexto social, cultural, econômico e político. Essa ambivalência pode estar presente dentro de uma mesma política, bem como pode criar empecilhos para a construção da intersetorialidade.

Quadro 3. Concepções de família e de apoio às famílias nas políticas públicas

\begin{tabular}{|c|c|c|c|}
\hline $\begin{array}{l}\text { Categoria de } \\
\text { análise }\end{array}$ & $\begin{array}{l}\text { Questões } \\
\text { analisadas }\end{array}$ & & Síntese dos resultados da análise \\
\hline \multirow[t]{5}{*}{$\begin{array}{l}\text { 3. Os sentidos } \\
\text { dados aos dife- } \\
\text { rentes arranjos } \\
\text { familiares na } \\
\text { política social }\end{array}$} & \multirow[t]{3}{*}{$\begin{array}{l}3.1 \text { Que concep- } \\
\text { ções de família } \\
\text { utiliza? Tais } \\
\text { concepções são } \\
\text { explicitadas ou } \\
\text { subentendidas? }\end{array}$} & Saúde & $\begin{array}{l}\text { No documento (S5), observa-se a confluência das } \\
\text { duas concepções: a familista, na dimensão do } \\
\text { cuidado, e a concepção crítica, potencializadora } \\
\text { da autonomia e da participação da família, nos } \\
\text { processos de controle social com vistas à garantia } \\
\text { de direitos e melhoria da qualidade dos serviços. }\end{array}$ \\
\hline & & Educação & $\begin{array}{l}\text { O resultado da pesquisa demonstrou uma predo- } \\
\text { minância da concepção familista, vinculada às } \\
\text { respostas que se espera da família, muitas vezes } \\
\text { vinculadas a um modelo de família nuclear, pois } \\
\text { demanda-se suporte e participação dos pais na } \\
\text { vida escolar dos filhos, parceria nas atividades, } \\
\text { sem considerar as novas configurações familiares } \\
\text { e a realidade de sobrevivência e/ou subemprego em } \\
\text { que vivem as famílias mais vulneráveis. }\end{array}$ \\
\hline & & $\begin{array}{l}\text { Assistência } \\
\text { Social }\end{array}$ & $\begin{array}{l}\text { Na Assistência Social, observa-se uma ambivalên- } \\
\text { cia entre o modelo familista e o crítico, pois há um } \\
\text { esforço da sua função protetiva como lugar do afeto, } \\
\text { cuidado, proteção, construção de identidade, cons- } \\
\text { trução de vínculos relacionais e de pertencimento, } \\
\text { e ao mesmo tempo um espaço de reprodução de } \\
\text { desigualdades e de violência. }\end{array}$ \\
\hline & $\begin{array}{l}3.2 \text { Que estraté- } \\
\text { gias de apoio às } \\
\text { famílias o docu- } \\
\text { mento busca de- } \\
\text { finir na política } \\
\text { pública? }\end{array}$ & Saúde & $\begin{array}{l}\text { No documento (S6), uma das estratégias de diálogo } \\
\text { é os agentes comunitários manterem contato per- } \\
\text { manente com as famílias e desenvolverem ações } \\
\text { educativas que visem à promoção da saúde e à } \\
\text { prevenção das doenças, de acordo com o planeja- } \\
\text { mento da equipe. }\end{array}$ \\
\hline & & Educação & $\begin{array}{l}\text { Fortalecer o acompanhamento e o monitoramento } \\
\text { do acesso, da permanência e do aproveitamento } \\
\text { escolar dos beneficiários de programas de trans- } \\
\text { ferência de renda, bem como das situações de } \\
\text { discriminação, preconceitos e violências na escola, } \\
\text { visando o estabelecimento de condições adequa- } \\
\text { das para o sucesso escolar dos(as) alunos(as), em }\end{array}$ \\
\hline
\end{tabular}


Quadro 3. Continuação

\begin{tabular}{|l|l|l|l|}
\hline $\begin{array}{c}\text { Categoria de } \\
\text { análise }\end{array}$ & $\begin{array}{c}\text { Questões } \\
\text { analisadas }\end{array}$ & $\begin{array}{l}\text { Síntese dos resultados da análise } \\
\text { colaboração com as famílias e com órgãos públicos } \\
\text { de Assistência Social, Saúde e proteção à infância, } \\
\text { adolescência e juventude (E3). }\end{array}$ \\
\hline & $\begin{array}{c}\text { Assistência } \\
\text { Social }\end{array}$ & $\begin{array}{l}\text { Aponta, como estratégias, o apoio à família, pro- } \\
\text { gramas de transferência de renda para famílias } \\
\text { pobres e extremamente pobres e o trabalho social } \\
\text { com famílias (AS2). }\end{array}$ \\
\hline
\end{tabular}

Fonte: Elaboração das autoras.

No Quadro 4, são apresentados exemplos dos sentidos dados à capacidade das famílias de participarem das políticas públicas, ou seja, de serem vistas como sujeitos de direitos. Os dados apontam que, ao menos na teoria, os discursos das políticas públicas examinadas dão suporte ao papel ativo e participativo das famílias. Ou seja, adotam o valor da participação expresso na CF88 e da autonomia como requisito importante do exercício da cidadania. Porém a análise também mostra a necessidade de fazer as articulações necessárias para que essa participação se efetive, criando estratégias, instrumentais, meios e incentivos para a participação.

Quadro 4. Sentidos dados à capacidade da família de dialogar com a política pública, de participar e de desenvolver a sua autonomia

\begin{tabular}{|c|c|c|c|}
\hline $\begin{array}{l}\text { Categoria de } \\
\text { análise }\end{array}$ & $\begin{array}{l}\text { Questões } \\
\text { analisadas }\end{array}$ & & Síntese dos resultados da análise \\
\hline \multirow[t]{3}{*}{$\begin{array}{l}\text { 4. Sentido dado } \\
\text { à capacidade de } \\
\text { a família parti- } \\
\text { cipar e decidir } \\
\text { nas políticas } \\
\text { públicas }\end{array}$} & \multirow{3}{*}{$\begin{array}{l}4.1 \text { Que estraté- } \\
\text { gias estão previs- } \\
\text { tas para o diálogo } \\
\text { com as famílias? } \\
\text { Que relações de- } \\
\text { vem ser desen- } \\
\text { volvidas com as } \\
\text { famílias? }\end{array}$} & Saúde & $\begin{array}{l}\text { Uma das estratégias de diálogo visa o fortalecimen- } \\
\text { to das instâncias de controle social das políticas } \\
\text { públicas e dos canais de interação com o usuário } \\
\text { para a garantia de participação popular no processo } \\
\text { de formulação, controle e avaliação das políticas de } \\
\text { saúde e criação de ouvidoria em saúde (S9). }\end{array}$ \\
\hline & & Educação & $\begin{array}{l}\text { Uma estratégia é o estímulo à constituição e ao } \\
\text { fortalecimento de conselhos escolares e conselhos } \\
\text { municipais de educação, como instrumentos de } \\
\text { participação e fiscalização na gestão escolar e } \\
\text { educacional, por meio de programas de formação } \\
\text { de conselheiros, assegurando-se funcionamento } \\
\text { autônomo (E3). }\end{array}$ \\
\hline & & $\begin{array}{l}\text { Assistência } \\
\text { Social }\end{array}$ & $\begin{array}{l}\text { Investimento em atividades coletivas no âmbito } \\
\text { do trabalho social com famílias para discussão e } \\
\text { reflexão de projetos coletivos e para o protagonismo } \\
\text { na comunidade. }\end{array}$ \\
\hline
\end{tabular}


Quadro 4. Continuação

\begin{tabular}{|c|c|c|c|}
\hline $\begin{array}{l}\text { Categoria de } \\
\text { análise }\end{array}$ & $\begin{array}{l}\text { Questões } \\
\text { analisadas }\end{array}$ & & Síntese dos resultados da análise \\
\hline & \multirow[t]{3}{*}{$\begin{array}{l}4.2 \text { Que valor se } \\
\text { dá à participação } \\
\text { da família nas po- } \\
\text { líticas públicas e } \\
\text { nas instâncias de } \\
\text { controle social? }\end{array}$} & Saúde & $\begin{array}{l}\text { Aborda a implementação de políticas de estímulo } \\
\text { à participação de usuários e entidades da socieda- } \\
\text { de no processo de avaliação dos serviços do SUS. } \\
\text { E também a realização de pesquisas visando à } \\
\text { produção do conhecimento no campo da ouvidoria } \\
\text { em Saúde, para subsidiar a formulação de políticas } \\
\text { de gestão do SUS (S9). }\end{array}$ \\
\hline & & Educação & $\begin{array}{l}\text { Preconiza-se o estímulo à participação e à consulta } \\
\text { de profissionais da educação, alunos(as) e seus } \\
\text { familiares na formulação dos projetos político- } \\
\text {-pedagógicos, currículos escolares, planos de gestão } \\
\text { escolar e regimentos escolares, assegurando a } \\
\text { participação dos pais na avaliação de docentes e } \\
\text { gestores escolares (E3). }\end{array}$ \\
\hline & & $\begin{array}{l}\text { Assistência } \\
\text { Social }\end{array}$ & $\begin{array}{l}\text { Fomento à participação da família no processo de } \\
\text { gestão democrática do Suas por meio das instâncias } \\
\text { de controle social. }\end{array}$ \\
\hline & \multirow[t]{3}{*}{$\begin{array}{l}4.3 \text { Como a auto- } \\
\text { nomia da família } \\
\text { é abordada na } \\
\text { política social? }\end{array}$} & Saúde & $\begin{array}{l}\text { A autonomia é entendida na corresponsabilidade da } \\
\text { família na promoção do cuidado com a saúde e na } \\
\text { elaboração dos planos, programas, projetos e ações } \\
\text { voltadas para crianças, adultos, idosos, pessoas com } \\
\text { deficiência etc. (S8). }\end{array}$ \\
\hline & & Educação & $\begin{array}{l}\text { A autonomia está na participação da comunidade } \\
\text { escolar no planejamento e na aplicação dos recursos, } \\
\text { visando a ampliação da transparência e o efetivo } \\
\text { desenvolvimento da gestão democrática, com apoio } \\
\text { técnico e financeiro da gestão escolar e transferên- } \\
\text { cia direta de recursos financeiros (E3). }\end{array}$ \\
\hline & & $\begin{array}{l}\text { Assistência } \\
\text { Social }\end{array}$ & $\begin{array}{l}\text { A autonomia é abordada como prerrogativa para } \\
\text { o controle da política e resultado do protagonismo } \\
\text { dos usuários na construção de projetos de vida e } \\
\text { na organização interna para a proteção de seus } \\
\text { membros (AS2). }\end{array}$ \\
\hline
\end{tabular}

Fonte: Elaboração das autoras.

O Quadro 5 mostra que os documentos analisados guardam coerência com a CF88 na defesa da intersetorialidade e da integralidade das políticas públicas na proteção social aos cidadãos. Entretanto, também se percebe a necessidade de se identificar como e por quais meios essa intersetorialidade poderia ser implementada e consolidada. 
Quadro 5. Sentidos dados à intersetorialidade na política pública

\begin{tabular}{|c|c|c|c|}
\hline $\begin{array}{l}\text { Categoria de } \\
\text { análise }\end{array}$ & $\begin{array}{l}\text { Questões } \\
\text { analisadas }\end{array}$ & & Síntese dos resultados da análise \\
\hline \multirow[t]{3}{*}{$\begin{array}{l}\text { 5. Intersetoria- } \\
\text { lidade entre as } \\
\text { políticas públi- } \\
\text { cas na proteção } \\
\text { social às famílias }\end{array}$} & \multirow[t]{3}{*}{$\begin{array}{l}5.1 \text { Que lugar } \\
\text { tem a interse- } \\
\text { torialidade no } \\
\text { desenvolvimen- } \\
\text { to das políticas } \\
\text { públicas? }\end{array}$} & Saúde & $\begin{array}{l}\text { A intersetorialidade é citada nas situaçães em que } \\
\text { o paciente está há longo tempo hospitalizado, ou } \\
\text { para situações de grave dependência institucional } \\
\text { decorrentes de seu quadro clínico, ou ainda pela } \\
\text { ausência de suporte social em que o planejamen- } \\
\text { to da política específica de alta complexidade e } \\
\text { reabilitação psicossocial assistida (S4). No Pro- } \\
\text { grama de Saúde da família, o desenvolvimento de } \\
\text { ações intersetoriais está voltado para a formação } \\
\text { de parcerias e integração de projetos sociais e } \\
\text { setores afins (S6). }\end{array}$ \\
\hline & & Educação & $\begin{array}{l}\text { A intersetorialidade está na articulação das } \\
\text { políticas educacionais com as demais políticas } \\
\text { sociais, particularmente as culturais. Propõe ainda } \\
\text { articulação em caráter complementar, com progra- } \\
\text { mas de orientação e apoio às famílias conjunta- } \\
\text { mente às áreas da Saúde e Assistência Social (E3). }\end{array}$ \\
\hline & & $\begin{array}{c}\text { Assistência } \\
\text { Social }\end{array}$ & $\begin{array}{l}\text { No âmbito da Assistência Social, a intersetoria- } \\
\text { lidade é uma articulação entre setores e saberes, } \\
\text { com vistas à promoção de respostas integradas e } \\
\text { com objetivos comuns, que se materializam na ma- } \\
\text { neira de trabalhar, governar e construir políticas } \\
\text { públicas que produzam efeitos mais significativos } \\
\text { na vida da população (AS3). }\end{array}$ \\
\hline
\end{tabular}

Fonte: Elaboração das autoras.

Na Assistência Social, para Fadul (2014), o conceito de família reafirma os princípios da matricialidade sociofamiliar e rompe com o paradigma hegemônico da família nuclear burguesa. Sposati (2009) discute que tal ênfase na matricialidade familiar reforça o lugar da família como núcleo protetivo intergeracional, no campo das relações afetivas, materiais e sociais. Porém também envolve tensões entre a "expectativa de capacidade protetiva da família e a presença do Estado na regulação e administração dos processos sociais", o que pode levar a um viés moralista na "regulação do comportamento familiar" (p. 43). Esse viés pode ocorrer também nas políticas de Educação e Saúde, quando não consideram as vulnerabilidades associadas aos contextos sociais mais amplos que reforçam situações de subalternidade vividas pelas famílias. 
Uma visão crítica reafirma a família como sujeito de direitos, dentro de seu contexto sociocultural e político (Mioto, 2008), e assume a proteção social como direito. A finalidade é criar novos canais de proteção "com viés emancipatório e participativo em que as famílias sejam tratadas como protagonistas, e não como coadjuvantes" nos processos democráticos (Orozimbo, 2017, p. 167).

\section{Considerações finais}

Pensar os sentidos atribuídos à família na proteção social envolve desafios para as políticas públicas, como (1) rever a forma como atuam com as famílias; (2) compreender a complexidade dos fenômenos sociais que interferem nas relações e dinâmicas familiares; e (3) produzir mecanismos de gestão horizontalizados na formulação, implementação e avaliação das políticas direcionadas às famílias, bem como de espaços e estratégias para a sua participação (Orozimbo, 2017).

Sugere-se, a partir de Mioto e Prá (2015), que as políticas devem ser pensadas objetivando a desfamiliarização e da desmercadorização da atenção, a fim de promover a sua inclusão social por meio de uma rede intersetorial, com oferta universal de serviços sob a responsabilidade do Estado e provimento de suporte para o cumprimento da função de proteção familiar e dos direitos, na perspectiva de emancipação social e cidadania, contribuindo desta forma para o desenvolvimento social.

Considerou-se importante identificar um novo olhar sobre a família, no sentido de reconhecer os seus direitos, sua necessidade de apoio e a importância da sua participação social. Como dificuldades, aponta-se que a precariedade no provimento de políticas públicas mais equânimes, em qualidade e quantidade suficiente, causa "desproteção social pela ausência ou insuficiência das ações do Estado e a transferência da responsabilidade de proteção para as famílias" (Orozimbo, 2017, p. 167).

É necessário rever como a rede de serviços tem fomentado e investido no potencial de participação cidadã das famílias (Orozimbo, 2017). Isto 
implica o investimento do Estado na superação daquilo que Demo (1995, p. 29) denomina de "pobreza política", que tolhe a oportunidade do cidadão e fomenta a resistência por meio do conhecimento, estratégia primordial para a politização e ampliação do poder de mobilização social, política e ideológica na luta por uma sociedade justa e equânime.

Também pode ser identificada a necessidade de investimento em capacitações para gestores e técnicos, de forma que reflitam sobre os sentidos atribuídos às famílias nas políticas públicas, numa perspectiva crítica, buscando avançar na interlocução contínua com os direitos fundamentais, os direitos humanos e a cidadania (Orozimbo, 2017).

Uma das dificuldades para integrar ações intersetoriais resulta de concepções culturalmente arraigadas sobre a relação entre a família e a proteção social. A análise revela a necessidade de fortalecimento dos processos democráticos na gestão social das políticas sociais, buscando a sua interação para o enfrentamento das desigualdades sociais (Orozimbo, 2017). Também é importante avançar na construção da intersetorialidade, tanto nas concepções teóricas como nos mecanismos de gestão e proposição de instrumentais para a sua efetivação, aliada à participação social.

Esta pesquisa não pretendeu ser exaustiva, apresentando o limite de ser apenas documental. Contudo, envidou esforços para oferecer uma reflexão sobre a abordagem da família nas políticas sociais. Dessa maneira, também aponta para a necessidade de novas pesquisas sobre fatores que favorecem ou dificultam a efetivação e a garantia de direitos, bem como a intersetorialidade, no enfrentamento das expressões da questão social, envolvendo a família - e as famílias singulares - nos diferentes contextos sociais.

\section{Referências}

BRASIL. Lei n. 8.142, de 28 de dezembro de 1990. Dispõe sobre a participação da comunidade na gestão do Sistema Único de Saúde (SUS) e sobre as transferências intergovernamentais de recursos financeiros na área da saúde e dá outras providências. Ministério da Saúde, Brasília, 1990. Disponível em: http://www.planalto.gov.br/ccivil_03/ LEIS/L8742compilado.htm. Acesso em: 27 nov. 2018. 
BRASIL. Lei n. 8.742, de 7 de dezembro de 1993 - Lei Orgânica da Assistência Social. Dispõe sobre a organização da Assistência Social e dá outras providências. Diário Oficial da União, Brasília, 1993.

Ministério do Desenvolvimento Social e Combate à Fome. Política Nacional de Assistência Social — PNAS/2004. Brasília, 2004.

Portaria n. 2.528, de 19 de outubro de 2006. Aprova a Política Nacional de Saúde da Pessoa Idosa. Diário Oficial da União, Brasília, 2006. Disponível em: http://bvsms.saude. gov.br/bvs/saudelegis/gm/2006/prt2528_19_10_2006.html. Acesso em: 27 nov. 2018.

Ministério do Desenvolvimento Social e Combate à Fome. Orientações técnicas: Centro de Referência de Assistência Social — CRAS. 1. ed. Brasília, 2009.

Ministério do Desenvolvimento Social e Combate à Fome. Secretaria Nacional de Assistência Social. Orientações técnicas sobre o trabalho social com famílias do Serviço de Proteção e Atendimento Integral à Família - PAIF. Brasília, 2012. v. 2. Disponível em: fpabramo.org.br/acervosocial/wp-content/uploads/sites/7/2017/08/043.pdf. Acesso em: 27 nov. 2018.

Lei n. 13.005, de 25 de junho de 2014. Aprova o Plano Nacional de Educação PNE e dá outras providências. Diário Oficial da República Federativa do Brasil, Brasília, 2014. Disponível em: http://www.planalto.gov.br/ccivil_03/_Ato2011-2014/2014/Lei/ L13005.htm. Acesso em: 27 nov. 2018.

Ministério do Desenvolvimento Social. Secretaria Nacional de Assistência Social. Concepção de convivência e fortalecimento de vínculos. Brasília, 2015. Disponível em: http://www.mds.gov.br/webarquivos/publicacao/assistencia_social/Cadernos/concepcao_ fortalecimento_vinculos.pdf. Acesso em: 27 nov. 2018.

CARNEIRO, Carla Bronzo. Exclusão: delimitação conceitual e os desafios para a mensuração. Pensar BH-Política Social, Belo Horizonte, v. 25, p. 12-19, mar. 2010.

CARVALHO, Inaiá M. M. de; ALMEIDA, Paulo H. de. Família e proteção social. São Paulo em Perspectiva, São Paulo, v. 17, p. 109-122, 2003.

COTTA, Tereza C. S. Visões de proteção social e transferência de renda condicionada no Brasil e no México. 2009. 350 f. Tese (Doutorado) - Curso de Doutorado em Estudos Comparativos Sobre as Américas, Universidade de Brasília, Brasília, 2010. Disponível em: http://repositorio.unb.br/handle/10482/4408. Acesso em: 27 nov. 2018.

DEMO, Pedro. Cidadania tutelada e cidadania assistida. Campinas. SP: Autores Associados, 1995.

FADUL, Fabiana Meijon. O Trabalho Social com Famílias no Âmbito da Proteção Social Básica: diálogos e conflitos no campo discursivo da Assistência Social. $154 \mathrm{f}$. Dissertação (Mestrado) - Curso de Mestrado Profissional em Gestão Social, Educação e Desenvolvimento Local, Centro Universitário Una, Belo Horizonte, 2014. 
FAIRCLOUGH, Norman. Language and Power. Londres: Nova York, 1989. 259 p.

Discurso e mudança social. Brasília: Universidade de Brasília, 2001. 316 p.

Analyzing Discourse: Textual Analysis for Social Research. Londres: Routledge, 2003. 270 p.

A dialética do discurso. Revista Teias, Rio de Janeiro, v. 11, n. 22, p. 225-234, 2010.

; MELO, I. F. de. Análise crítica do discurso como método em pesquisa social científica. Linha D’Água, São Paulo, v. 25, n. 2, p. 307-329, dez. 2012. Disponível em: http://www.revistas.usp.br/linhadagua/article/view/47728. Acesso em: 27 nov. 2018.

FARIA, Carlos Aurélio Pimenta de. Fundamentos para a formulação e análise de políticas e programas de atenção à família. In: CARNEIRO, Carla Bronzo L.; COSTA, Bruno L. D. (org.). Gestão social: o que há de novo? Belo Horizonte: Fundação João Pinheiro, 2004. v. 1 , p. $67-80$.

FOUCAULT, M. A ordem do discurso: aula inaugural no College de France, pronunciada em 2 de dezembro de 1970. Tradução: Laura Fraga de Almeida Sampaio. São Paulo: Loyola, 2014.

JACCOUD, Luciana. Assistência Social e construção do Suas - balanço e perspectivas: o percurso da Assistência Social como política de direitos e a trajetória necessária. In: CRUS, José Ferreira da et al. (org.). Coletânea de artigos comemorativos dos 20 anos da Lei Orgânica de Assistência Social. Brasília: MDS, 2013. p. 42-65. Disponível em: http:// www.mds.gov.br/webarquivos/publicacao/assistencia_social/Livros/20anosLOAS.pdf. Acesso em: 17 fev. 2019.

MEDEIROS, Alana C. B. de. Concepções de família presentes no Congresso Brasileiro de Assistentes Sociais. Temporalis, [S.1.], v. 2, n. 28, p. 275-296, nov. 2014. Disponível em: http://periodicos.ufes.br/temporalis/article/view/7192. Acesso em: 27 nov. 2018.

MIOTO, Regina C. T. A família no ensino de graduação em Serviço Social: uma experiência em construção na Universidade Federal de Santa Catarina. In: DE MARTINO, M.; GABIN, B. (org.). Prácticas pedagógicas y modalidades de supervisión en el área de família. Montevidéu: Tradinco, 2008. p. 57-70.

; PRÁ, Keli R. dal. Serviços sociais e responsabilização da família: contradições da política social brasileira. In: MIOTO, Regina C. T.; CAMPOS, Marta S.; CARLOTO, Cássia M. (org.). Familismo, direitos e cidadania: contradições da política social. São Paulo: Cortez, 2015. p. 147-178.

OROZIMBO, Elizete Matias Barbosa. Família e Proteção social: sentidos construídos no campo discursivo das políticas públicas a partir da Constituição Federal de 1988. Dissertação (Mestrado) - Curso de Mestrado Profissional em Gestão Social, Educação e Desenvolvimento Local, Centro Universitário Una, Belo Horizonte, 2017. 
OROZIMBO, Elizete Matias Barbosa; AFONSO, Maria Lucia Miranda. Os desafios de sustentar a intersetorialidade nas políticas de Saúde, Educação e Assistência Social. In: Romagnoli, Roberta Carvalho (org.). A intersetorialidade e seus desafios. Editora CRV Curitiba. 2018, p. 147-168.

PEDROSA, Cleide E. F. Análise crítica do discurso. In: IX CNLF. Livro de resumo do IX CNLF. Rio de Janeiro, 2005. Disponível em: http://www.filologia.org.br/ixcnlf/3/04.htm. Acesso em: 17 fev. 2019.

RESENDE, Viviane M. Análise de discurso crítica. 2. ed. São Paulo: Contexto, 2011.

SARAIVA, Luís Fernando de Oliveira. A familiarização da assistência social: promoção de direitos e gestão da vida no encontro entre vulnerabilidades, (des) proteção e periculosidade. São Paulo, 2016. Disponível em: http://www.teses.usp.br/teses/disponiveis/47/47134/tde16082016-102659/pt-br.php. Acesso em: 27 nov. 2019.

SOUZA, Marcelo M. C. de. A importância de se conhecer melhor as famílias para a elaboração de políticas sociais na América Latina. Texto para discussão Ipea, Rio de Janeiro, n. 699, 2000. Disponível em: http:/www.ipea.gov.br/agencia/images/stories/ PDFs/TDs/td_0699.pdf. Acesso em: 27 nov. 2018.

SPOSATI, Aldaíza. Modelo brasileiro de proteção social não contributiva: concepções fundantes. In: MINISTÉRIO DO DESENVOLVIMENTO SOCIAL E COMBATE À FOME (org.). Concepção e gestão da proteção social não contributiva no Brasil. Brasília: Unesco, 2009. p. 13-55.

TEIXEIRA, Solange M. Política social contemporânea: a família como referência para as políticas sociais e para o trabalho social. In: MIOTO, R. C. T.; CAMPOS, M. S.; CARLOTO, C. M. (org.). Familismo, direito e cidadania: contradições da política social. São Paulo: Cortez, 2015. p. 211-239.

\section{Sobre as autoras}

Elizete Matias Barbosa Orozimbo - Assistente social. Mestre em Gestão Social, Educação e Desenvolvimento Local.

E-mail: elizetembo@yahoo.com.br

Maria LÚcia Miranda Afonso - Psicóloga. Mestre e doutora em Educação. E-mail: luafonso@yahoo.com 